Article

\title{
Synthesis, Characterization, and Analysis of Hybrid Carbon Nanotubes by Chemical Vapor Deposition: Application for Aluminum Removal
}

\author{
Alfarooq O. Basheer ${ }^{1, * \mathbb{C}}$, Marlia M. Hanafiah ${ }^{1,2}$, Mohammed Abdulhakim Alsaadi ${ }^{3,4,5} \mathbb{D}$, \\ Wan Zuhairi Wan Yaacob ${ }^{1}$ and Y. Al-Douri ${ }^{3,6,7}$ \\ 1 Department for Earth Sciences and Environment, Faculty of Science and Technology, \\ Universiti Kebangsaan Malaysia, Bangi 43600, Selangor, Malaysia; yaacobzw@ukm.edu.my \\ 2 Centre for Tropical Climate Change System, Institute of Climate Change, Universiti Kebangsaan Malaysia, \\ Bangi 43600, Selangor, Malaysia; mhmarlia@ukm.edu.my \\ 3 Nanotechnology and Catalysis Research Center (NANOCAT), University of Malaya, \\ Kuala Lumpur 50603, Malaysia; m.hakim@unizwa.edu.om (M.A.A.); yarub@um.edu.my (Y.A.-D.) \\ 4 National Chair of Materials Science and Metallurgy, University of Nizwa, Nizawa 611, Oman \\ 5 Department of Civil Engineering, Almaref University College, Al-Anbar 31001, Iraq \\ 6 University Research Center, Cihan University Sulaimaniya, Sulaymaniyah 46002, Iraq \\ 7 Department of Mechatronics Engineering, Faculty of Engineering and Natural Sciences, \\ Bahcesehir University, 34349 Besiktas, Istanbul, Turkey \\ * Correspondence: p90670@siswa.ukm.edu.my
}

Received: 11 November 2019; Accepted: 13 December 2019; Published: 8 June 2020

\begin{abstract}
Hybrid carbon nanotubes (CNTs) are grown on biomass powder-activated carbon (bio-PAC) by loading iron nanoparticles (Fe) as catalyst templates using chemical vapor deposition (CVD) and using acetylene as carbon source, under specific conditions as reaction temperature, time, and gas ratio that are $550^{\circ} \mathrm{C}, 47 \mathrm{~min}$, and 1, respectively. Specifications of hybrid CNTs were analyzed and characterized using field emission scanning electron microscope (FESEM) with energy-dispersive X-ray spectroscopy (EDX), transmission electron microscopic (TEM), Fourier-transform infrared (FTIR), X-ray diffraction (XRD), thermogravimetric analysis (TGA), surface area Brunauer-Emmett-Teller (BET), and zeta potential. The results revealed the high quality and unique morphologies of hybrid CNTs. Furthermore, removal and capacity of $\mathrm{Al}^{3+}$ were optimized by response surface methodology (RSM). However, the results revealed that the pseudo-second-order model well represented adsorption kinetic data, while the isotherm data were effectively fitted using a Freundlich model. The maximum adsorption capacity was $347.88 \mathrm{mg} / \mathrm{g}$. It could be concluded that synthesized hybrid CNTs are a new cost-effective and promising adsorbent for removing $\mathrm{Al}^{3+}$ ion from wastewater.
\end{abstract}

Keywords: synthesis; carbon nanotubes; characterization; chemical vapor deposition; adsorption

\section{Introduction}

The environmental quality has been deteriorating on a global scale every day because of the rapid development of industrialization and increasing infrastructure. Industrial effluents, farm wastes, and sewage add major contaminants to the environment as they contain several toxic metals and organic and inorganic pollutants. Toxic metal pollution is caused by the industrial waste discharged in the water ecosystems, which severely threaten humanity and all living creatures on earth. Aluminum is known to be extremely reactive to oxygen and carbon, and a high level of aluminum can harm human health because of its intoxication and result in severe diseases. Hence, it is recognized as the 
main factor contributing to autism spectrum disorders, Alzheimer's disease, and neurotoxicity of the central nervous system [1-3].

Consequently, drinking water should not contain more than $0.05-0.20 \mathrm{mg} / \mathrm{L}$ aluminum concentration, as reported by the Environmental Protection Agency (EPA) [4]. It is thus crucial to remove aluminum before it is discharged into aquatic environments.

To remove toxic metal pollution from wastewater, several conventional methods have been implemented. Those metals can be chemically precipitated with hydroxides, chelating precipitation sulfides, membrane filtration, coagulation and flocculation, bioadsorbents, adsorption by porous carbon materials, electrodialysis, ion exchange, flotation, and electrochemical treatments, such as electrochemical oxidation, electrocoagulation/electrocoagulation flotation, electrodialysis, and photoelectrochemical, sonoelectrochemical, and electrochemical reduction [5-9].

Of those techniques, adsorption is considered to be the superior technique because of its flexibility in design, operation, cost-effectiveness, and enabling large-scale applications. Thus, various types of component of adsorbents have been utilized for removal of toxic metals, such as sawdust [10], rice husks [11], maize cobs [12], granulated blast-furnace slag [13], kaolinitic and giru clay [14], aquatic plant [15], powder-activated carbon (PAC) [16], and nanomaterials [17].

Today, there is increasing interest in nanomaterials because of their excellent mechanical performance. One of the interesting nanomaterials is carbon nanotubes (CNTs), which are been widely studied and evaluated for water treatment because of their exceptional properties, including nanotubes' structure, easy separation, catalytic potential, high reactivity, small size, and large surface area, which can be effective adsorbents for several metals. CNTs are grown using several methods, such as arc discharge, laser ablation, and chemical vapor deposition (CVD). CVD technique is more effective as it is a cost-effective technique and provides high-purity material under controlled growth conditions [18].

As PAC enjoys wide precursor accessibility with its low cost and chemical alterations potentials, it is considered to be the ideal substrate for CVD. Typically, selective growth is easy to achieve by implementing a synthesis technique that used pre-patterned catalyst nanoparticles, including iron, nickel, molybdenum, aluminum, cobalt, and zirconium. Xiang et al. [19] and Mustafa et al. [20] reported synthesized CNTs on PAC using CVD in which the acetylene was utilized as the source of carbon along with several catalysts obtained from cobalt, iron, aluminum, and nickel. While Haiyam et al. synthesized carbon nanomaterials (CNMs) on commercial PAC loaded with nickel nanoparticles by using methane as a carbon source [21]. Arash et al. synthesized CNTs using CVD on silicon sheets loaded with iron and using molybdenum methane utilized as a carbon source [22]. Moreover, Zaho et al. synthesized a significant outcome concerning the CNTs by using CVD in water and implementing iron and molybdenum catalyst supported by a magnesium oxide substrate [23]. There was a reversal relationship between catalyst lifetime and CNT growth rate, as noted by Chen et al. [24]. Finally, Mamtm et al. reported that PAC could be a good precursor to CNT's growth [25]. It is believed that PAC's dose does not require any chemical or physical elimination from the functional bulk material, contrary to other substrates. Hybrid CNTs can be effectively defined as combinations of two or more materials, or of materials and space, assembled in such a way as to have attributes not offered by any one material alone. Furthermore, it was found that iron nanoparticles as catalyst and acetylene as carbon source could provide pure CNTs of high quality and density. The feature of this study was to shed some light on the unique hybrid CNTs growth and their magnetic properties, making it easier to separate it from the liquid.

The present study investigated the impact of synthesized hybrid CNTs on biomass (bio)-PAC as biomass precursor was loaded by iron nanoparticles (Fe) followed by CVD. The morphology and structure properties of hybrid CNTs were characterized and analyzed by energy-dispersive X-ray spectroscopy (EDX), field-emission scanning electron microscopy (FESEM), transmission electron microscopy (TEM), X-ray diffraction (XRD), Fourier-transform infrared spectroscopy (FTIR), thermogravimetric analysis (TGA), Brunauer-Emmett-Teller (BET), and zeta potential. The results 
showed that hybrid CNTs could easily separate from water because of hydrophobicity. This could provide a scalable process for industrial applications because of its facile operation and high removal performance and would be used as CNTs' new cost-effectiveness adsorbent. In addition, response surface methodology (RSM) with central composite design (CCD) was used for optimizing $\mathrm{Al}^{3+}$ removal. Moreover, adsorption models' kinetic and isotherms were also examined and discussed.

\section{Experimental}

\subsection{Materials and Reagents}

For this study, iron (III) nitrate nonahydrate $\mathrm{Fe}\left(\mathrm{NO}_{3}\right)_{3} \cdot 9 \mathrm{H}_{2} \mathrm{O}$ and acetone were purchased from Friendemann Schemicit (Selangor, Malaysia); aluminum standard solution $\mathrm{Al}\left(\mathrm{NO}_{3}\right)_{3} \cdot 9 \mathrm{H}_{2} \mathrm{O}$, hydrochloric acid $(\mathrm{HCl})$, and sodium hydroxide $(\mathrm{NaOH})$ were obtained from Merck (Selangor, Malaysia); and $\mathrm{C}_{2} \mathrm{H}_{2}, \mathrm{H}_{2}$, and $\mathrm{N}_{2}$ used for hybrid CNTs growth were purchased from Alpha Gas Solution (AGS) (Shah alam, Malaysia). The biomass powder-activated carbon (bio-PAC), which was fabricated and optimized by our group, was utilized for the rapid and cost-effective synthesis of hybrid CNTs [1].

\subsection{Synthesis of Hybrid CNTs}

\subsubsection{Catalyst Impregnation}

The Fe was utilized as a catalyst and added in $5 \mathrm{~mL}$ acetone, then mixed with $(2 \mathrm{~g})$ bio-PAC. However, the mixture was sonicated at $60^{\circ} \mathrm{C}$ for $99 \mathrm{~min}$ until the evaporation of acetone. Subsequently, the bio-PAC/Fe sample was dried at $105{ }^{\circ} \mathrm{C}$ for $24 \mathrm{~h}$. Then, the bio-PAC/Fe was calcinated at $400^{\circ} \mathrm{C}$ for $2 \mathrm{~h}$ under inert gas (purified $\mathrm{N}_{2}, 200 \mathrm{~mL} / \mathrm{min}$ ) [26].

\subsubsection{CVD Growth}

CNTs' growth was carried out by placing (300 mg) bio-PAC/Fe in a ceramic boat with a CVD reaction tube. A typical growth was accomplished by reduction under $\mathrm{H}_{2}$ at $550{ }^{\circ} \mathrm{C}$ with the flow $(160 \mathrm{~mL} / \mathrm{min})$. Thereafter, $\mathrm{C}_{2} \mathrm{H}_{2}$ was used as a carbon source and mixed with $\mathrm{H}_{2}$ at a 1:4 ratio. The reaction was passed through a heated reactor for $47 \mathrm{~min}$. After the completion of the reaction, the CVD reactor was cooled to room temperature under purified $\mathrm{N}_{2}$ flow rate $(200 \mathrm{~mL} / \mathrm{min})$, and then the CNTs growth sample was obtained. Figure 1 illustrates the preparation process of hybrid CNTs.

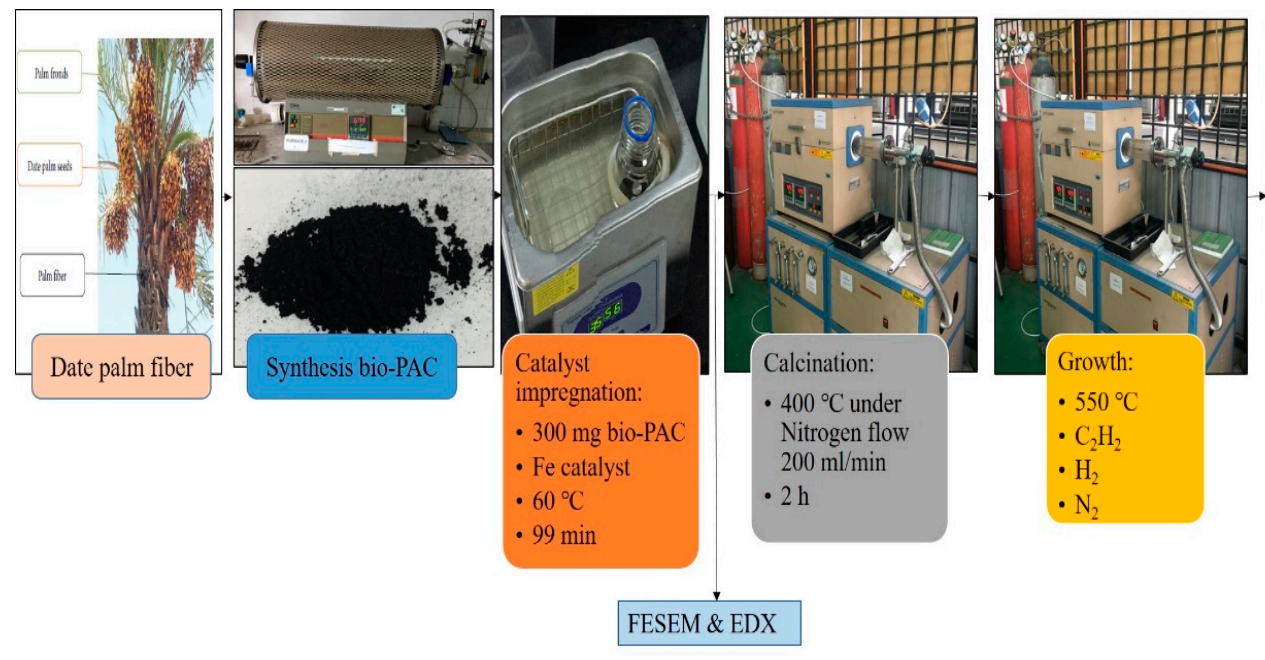

Figure 1. The preparation process for the synthesis of carbon nanotubes (CNTs).

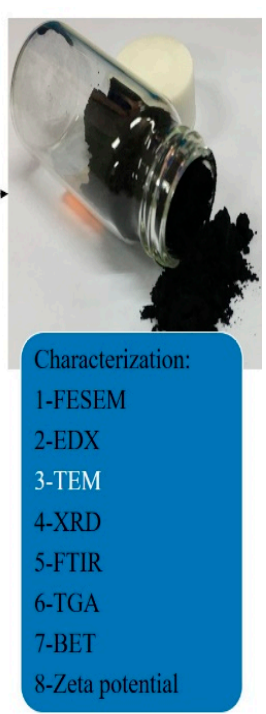




\subsection{Characterizations}

For hybrid CNTs, the surface morphology was analyzed and characterized using field emission scanning electron microscope (FESEM) with energy-dispersive X-ray spectroscopy (EDX), model ZEISS (Merlin, Cambridge, UK), and transmission electron microscope (TEM), (Hitachi-HT7700, Hitachinaka, Japan). The Fourier-transform infrared (FTIR) was utilized in order to analyze both surface functional groups and chemical bonds (Perkin Elmer, San Francisco, CA, USA). The structural phase was analyzed, relying on the powder X-ray diffraction (XRD) by a Burker AXS D8 advance (Karlsruhe, Germany). Whereas the determination of thermal oxidation was obtained from the thermogravimetric analysis (TGA) using the STA-6000 thermal analyzer (Perkin Elmer, Waltham, MA, USA). Moreover, pore size and surface area were calculated by the Brunauer-Emmett-Teller (BET) method (TriStar II 3020, Micromeritics, Norcross, GE, USA). Lastly, the zeta potential was utilized for the measurement of surface charge (Zeta Sizer, Worcestershire, UK).

\subsection{Adsorption Study}

\subsubsection{Experimental Design for Optimization of $\mathrm{Al}^{3+}$ Adsorption}

RSM method was utilized to optimize the removal of $\mathrm{Al}^{3+}$. The current study comprehensively examined the three parameters' impact and interaction, especially on the adsorption of hybrid CNTs' dosage of 5-20 mg, $\mathrm{pH}$ of 3-11, and contact time of 10-120 min. Table 1 displays the actual parameters of each run using the design of expert software (DoE, Stat-Ease, Minneapolis, MN, USA). For this optimization study, an initial aluminum concentration of $5 \mathrm{mg} / \mathrm{L}$ was used while agitating the flasks in a shaker at $180 \mathrm{rpm}$ [27].

Table 1. List of design of experiments runs and the actual values obtained from each response.

\begin{tabular}{cccccc}
\hline Run & $\begin{array}{c}\text { Dosage } \\
(\mathbf{m g} / \mathbf{g})\end{array}$ & $\mathbf{p H}$ & $\begin{array}{c}\text { Time } \\
(\mathbf{m i n})\end{array}$ & Response Removal (\%) & Response Capacity $(\mathbf{m g} / \mathbf{g})$ \\
\hline 1 & 5 & 11 & 10 & 93.62 & 93.62 \\
2 & 20 & 3 & 120 & 96.74 & 24.185 \\
3 & 12.50 & 7 & 65 & 84.68 & 33.872 \\
4 & 12.50 & 7 & 65 & 84.68 & 33.872 \\
5 & 12.50 & 7 & 10 & 87.86 & 35.144 \\
6 & 5 & 7 & 65 & 99.26 & 99.26 \\
7 & 20 & 11 & 120 & 7.08 & 1.77 \\
8 & 12.50 & 7 & 120 & 77.52 & 31.008 \\
9 & 12.50 & 3 & 65 & 9.08 & 3.632 \\
10 & 20 & 3 & 10 & 3.16 & 0.79 \\
11 & 12.50 & 7 & 65 & 84.68 & 33.872 \\
12 & 20 & 7 & 65 & 87.14 & 21.785 \\
13 & 12.50 & 11 & 65 & 96.84 & 38.736 \\
14 & 5 & 3 & 10 & 6.54 & 6.54 \\
15 & 5 & 3 & 120 & 14.54 & 14.54 \\
16 & 20 & 11 & 10 & 90.58 & 22.645 \\
17 & 5 & 11 & 120 & 97.52 & 97.52 \\
\hline
\end{tabular}

\subsubsection{Kinetic and Isotherm Adsorption}

The kinetic study specifies the crucial features of the ions transfer rate, from the solution to the surface of adsorbents, and its associated aspects. To determine the potential adsorbent application, the adsorption system kinetic is relied on to specify the adsorbent competence [28]. Establishing the adsorbent dosage and the $\mathrm{pH}$ parameters provides the kinetic study. Meanwhile, the $\mathrm{Al}^{3+}$ ion concentrations varied in their values ( 3 and $5 \mathrm{mg} / \mathrm{L}$ ) when the kinetic behavior was being studied, and they were managed at various contact times depending on the equilibrium state that was reached 
at $92 \mathrm{~min}$. This study applied three known kinetic models: the pseudo-first-order, pseudo-second-order, and the intraparticle diffusion model.

The optimum condition of $\mathrm{pH}$, amount of adsorbent dosage, and contact time were also taken into consideration when conducting the isotherm study along with the optimization study. The Freundlich and Langmuir isotherm models are the most known in the isotherm study, with both models frequently describing the $\mathrm{Al}^{3+}$ ions adsorption to the CNTs surface where the primary concentration of $\mathrm{Al}^{3+}$ varies from 3 to $40 \mathrm{mg} / \mathrm{L}$.

\section{Results and Discussion}

\subsection{Characterization and Analysis}

\subsubsection{FESEM, EDX, and TEM of Hybrid CNTs}

The morphologies of the hybrid CNTs were obtained using FESEM, as shown in Figure 2. Figure 2a shows that bio-PAC/Fe had a rough surface before growth and that Fe catalyst was dispersed. After $\mathrm{C}_{2} \mathrm{H}_{2}$ decomposition, the hybrid CNTs significantly showed network and agglomeration of CNTs grown on bio-PAC, providing robust evidence of Fe catalyst in the CNTs' growth, as shown in Figure 2c. Interestingly, the hybrid CNTs' diameter was between $23.02-27.93 \mathrm{~nm}$. Moreover, the proposed reason for the unique CNTs growth was the Fe bottom, and the entire Fe particle pushed off the bio-PAC, indicating a "base or root" growth model. This was caused by the weak interaction between Fe and PAC as the Fe catalyst was physically adsorbed on PAC [29,30].

Moreover, EDX analysis was used to determine elements of materials before and after growth. Figure 2b,d shows EDX profile for bio-PAC/Fe and hybrid CNTs, respectively. Figure $2 b$ shows that the Fe catalyst was successfully impregnated on bio-PAC. Consequently, Fe catalyst contributed to $2.9 \%$, and other impurities were also present, including $\mathrm{C}$ at $76.7 \%, \mathrm{O}$ at $10.5 \%$, and $\mathrm{Si}, \mathrm{Ca}, \mathrm{Al}$, and $\mathrm{Mg}$ at $<3 \%$. Furthermore, hybrid CNTs were observed and successfully grown on the bio-PAC surface, with $98.4 \%$ of the surface containing carbon. On the other hand, other elements dissipated from the sample, as shown in Figure $2 \mathrm{~d}$, because of the reaction process.

Furthermore, for more investigation and confirming the carbon nanotubes' growth, TEM analysis was conducted, as shown in Figure 3. TEM images revealed the internal structure of hybrid CNTs on the bio-PAC surface, which indicated a good quality of CNTs. Thus, the dark spots in the images represented the metallic catalyst clusters where the carbon atoms built up the CNTs' surrounding structure.

\subsubsection{X-ray Diffraction}

$\mathrm{XRD}$ is a rapid investigation method, mainly, which is utilized for the identification of a crystalline and molecular structure material and can provide information on unit cell dimensions [31,32]. Figure 4 shows the XRD pattern of hybrid CNTs; there was the strongest diffraction peak at $2 \theta=24.31$ corresponding to (002) reflection, which corresponded to the crystalline and cylinder structure [33]. However, there were the peaks at $2 \theta, 32.34^{\circ}, 40.57^{\circ}, 47.53^{\circ}, 54.33^{\circ}$, and $62.77^{\circ}$ corresponding to (100), (101), (004), (110), and (112) orientation, respectively. All peaks were well matched with the hexagonal graphite structure [34]. 

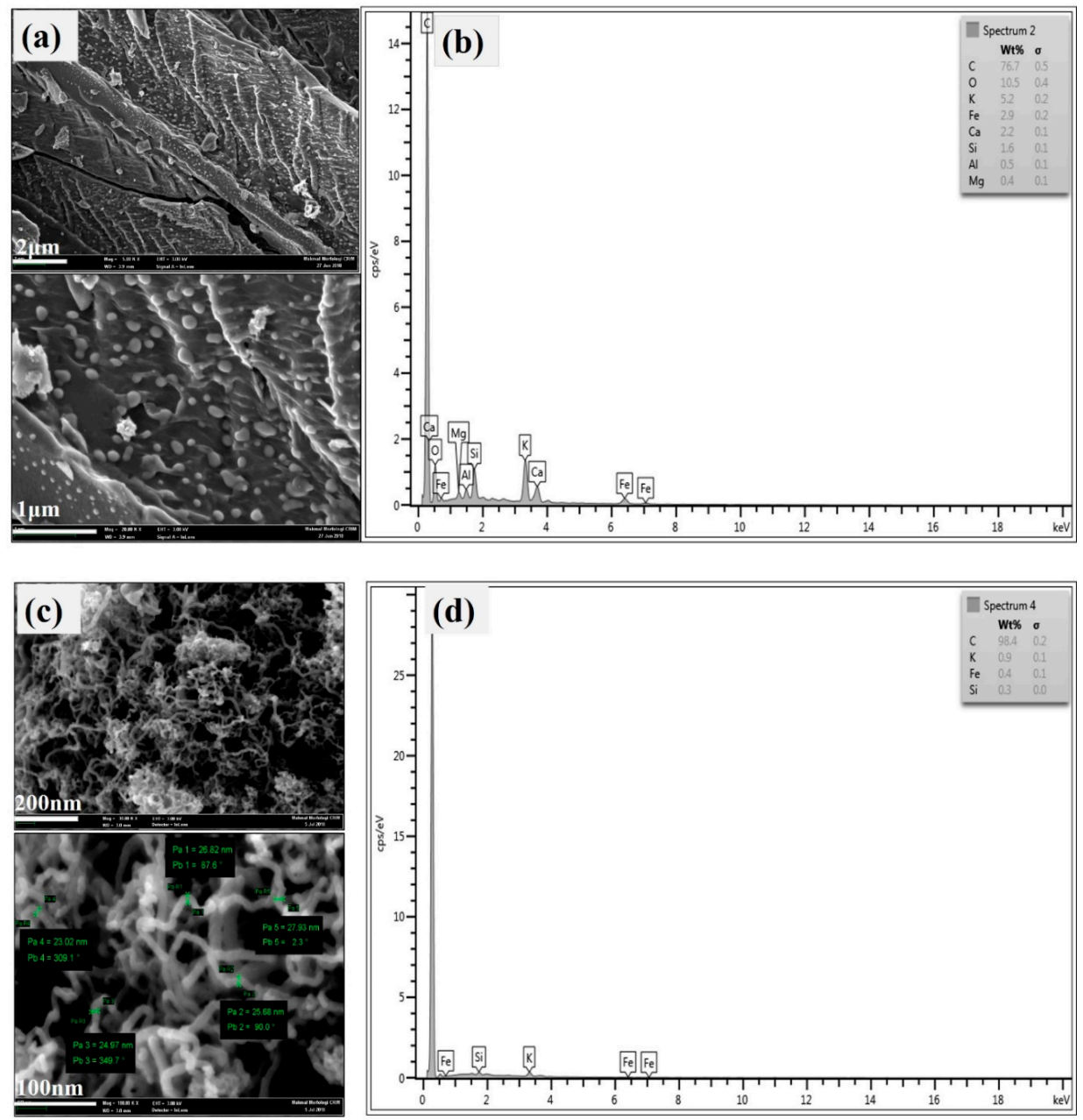

Figure 2. (a) FESEM (field emission scanning electron microscope) images; (b) EDX (energy-dispersive X-ray spectroscopy) profile of bio-PAC (biomass powder-activated carbon) loaded with Fe catalyst before growth, while (c) FESEM images and (d) EDX profile for hybrid CNTs after growth.

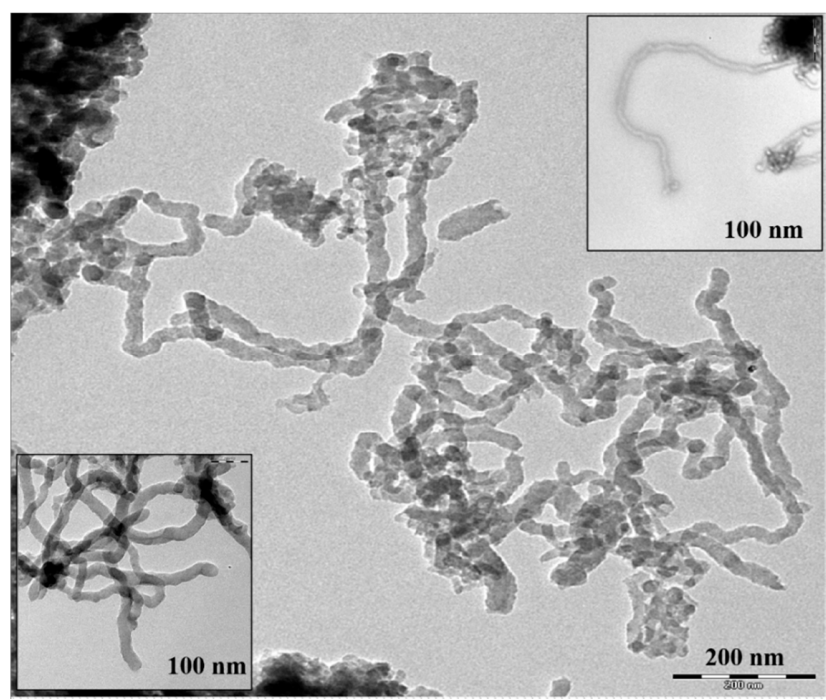

Figure 3. TEM (transmission electron microscope) images for hybrid CNTs. 


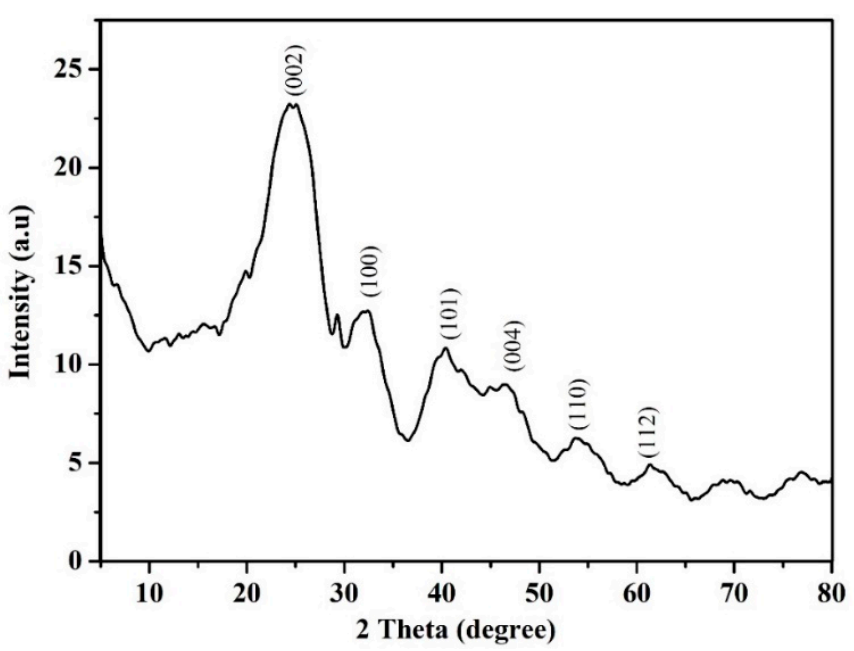

Figure 4. XRD (X-ray diffraction) pattern for hybrid CNTs.

\subsubsection{Fourier-Transform Infrared (FTIR) Analysis}

FTIR spectroscopy was used to determine the surface chemistry, i.e., characteristic functional groups of hybrid CNTs, as depicted in Figure 5. As seen in this figure, the weak peaks $3619 \mathrm{~cm}^{-1}$ and $3444 \mathrm{~cm}^{-1}$ were attributed to $\mathrm{O}-\mathrm{H}$ stretching vibration, indicating the hydroxyl group on hybrid CNTs surface [35]. The two broad peaks at 2897 and $2819 \mathrm{~cm}^{-1}$ could be assigned to C-H stretch vibration. Moreover, the sharp peaks at 2345 and $2227 \mathrm{~cm}^{-1}$ indicated $C \equiv C$ stretching vibrations, and the same results were reported by Minakshi et al. [36,37]. A sharp peak at $1685 \mathrm{~cm}^{-1}$ might be attributed to $\mathrm{C}=\mathrm{C}$ with $\mathrm{C}=\mathrm{O}$ conjugation or the interaction of the skeletal hybrid $\mathrm{CNTs}$ and carboxyl or ketone groups $[38,39]$. A strong and sharp peak located at $1555 \mathrm{~cm}^{-1}$ was attributed to the $\mathrm{C}=\mathrm{O}$ starching mode of the functional groups on the hybrid CNTs surface, originating from the hybridized carbon [40]. Obviously, peaks at 1392 and $1241 \mathrm{~cm}^{-1}$ might also be attributed to $\mathrm{N}-\mathrm{N}$ and $\mathrm{CH}-\mathrm{CH}_{3}$ bonds from the intercalated $\mathrm{N}$ atoms between the graphite layers of nanotube walls. The band at 1127 $\mathrm{cm}^{-1}$ indicated the $\mathrm{C}-\mathrm{O}$ stretching vibrations in alcohols, phenols, or ether or ester groups [41]. A sharp peak at $867 \mathrm{~cm}^{-1}$ was assigned to $\mathrm{CH}_{3}$ group vibration.

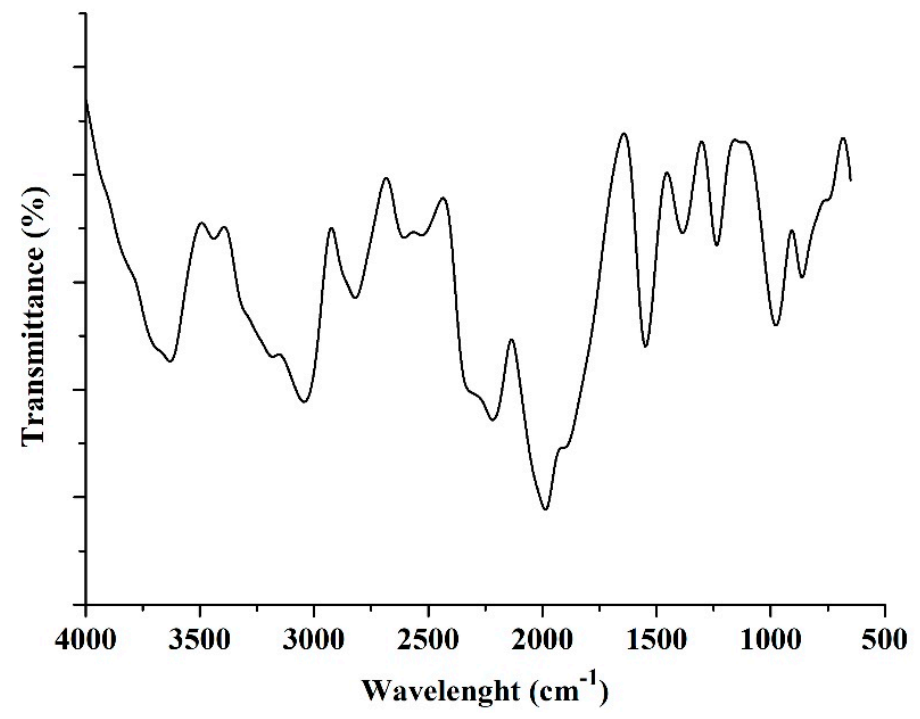

Figure 5. FTIR (Fourier-transform infrared) spectra of hybrid CNTs. 


\subsubsection{Thermogravimetric Analysis (TGA)}

TGA was employed to measure the thermal stability of hybrid CNTs. TGA curve, presented in Figure 6, shows a small weight loss resulting from the water removal at approximately $200{ }^{\circ} \mathrm{C}$. The elimination of carbon, along with the oxidation of nanotubes, which occurred at $650-750{ }^{\circ} \mathrm{C}$, was the reason behind the prevailing weight loss steps. However, the weight loss was $18.75 \%$ in the temperature range from 100 to $1000^{\circ} \mathrm{C}$, indicating the decomposition of formed carbonaceous material. The results were confirmed with FTIR spectra, as previously illustrated in Figure 4. Moreover, the activation energy of hybrid CNTs oxidation depended on several factors, such as the number of walls, defects, and presence of impurities. Similarly, Misra et al. recounted certain parallel trends concerning the thermogravimetric profiles [42]. Furthermore, when the temperature raised above $1000{ }^{\circ} \mathrm{C}$, the hybrid CNTs were believed to be thermally stable as there was no further decomposition detected.

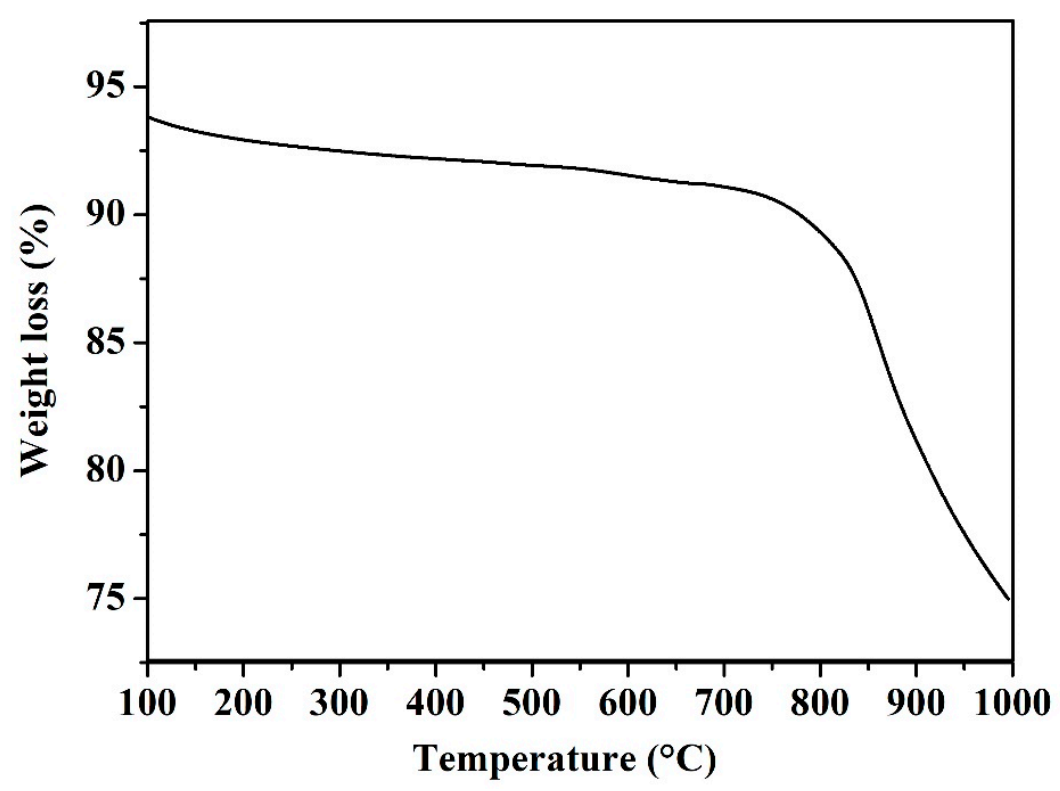

Figure 6. TGA (thermogravimetric analysis) of hybrid CNTs.

\subsubsection{Brunauer-Emmett-Teller (BET)}

$\mathrm{N}_{2}$ adsorption-desorption isotherms of hybrid CNTs are shown in Figure 7. According to the classification by IUPAC, A-type IV isotherm was observed, which demonstrates the generation of mesopores resulting from hybridization and hysteresis loop corresponding to type H3 [43]. This phenomenon was observed for hybrid CNTs prepared using other substrates [44]. Grown hybrid CNTs decreased in the surface area of $71.42 \mathrm{~m}^{2} / \mathrm{g}$ and pore-volume $0.230 \mathrm{~m}^{3} / \mathrm{g}$ than bio-PAC because of some pores impregnated with Fe nanoparticles (catalyst) for CNTs' growth. The pore size indicated that mesopores, which were $12 \mathrm{~nm}$, originated from the void spaces between nanotubes and were dominant. Table 2 shows the comparison between surface area, pore-volume, and pore size of different synthesis nanomaterials.

Table 2. BET (Brunauer-Emmett-Teller) surface area, pore-volume, and pore size of different adsorbents.

\begin{tabular}{ccccc}
\hline Materials & BET Surface Area $\left(\mathbf{m}^{2} / \mathbf{g}\right)$ & Pore-Volume $\left(\mathbf{m}^{3} / \mathbf{g}\right)$ & Pore Size $(\mathbf{n m})$ & References \\
\hline Hybrid CNTs & 71.24 & 0.230 & 12 & This work \\
Synthesized CNTs & 57.35 & 0.01 & 10 & {$[45]$} \\
$\mathrm{CNT} / \mathrm{ZnCo}_{2} \mathrm{O}_{4}$ & 67.60 & 1.103 & - & {$[46]$} \\
$\mathrm{CNMH}$ & 164.60 & 0.29 & 9 & {$[47]$} \\
$\mathrm{CNT} / \mathrm{TiO}_{2}$ & 51.44 & 0.67 & 9.33 & {$[48]$} \\
\hline
\end{tabular}




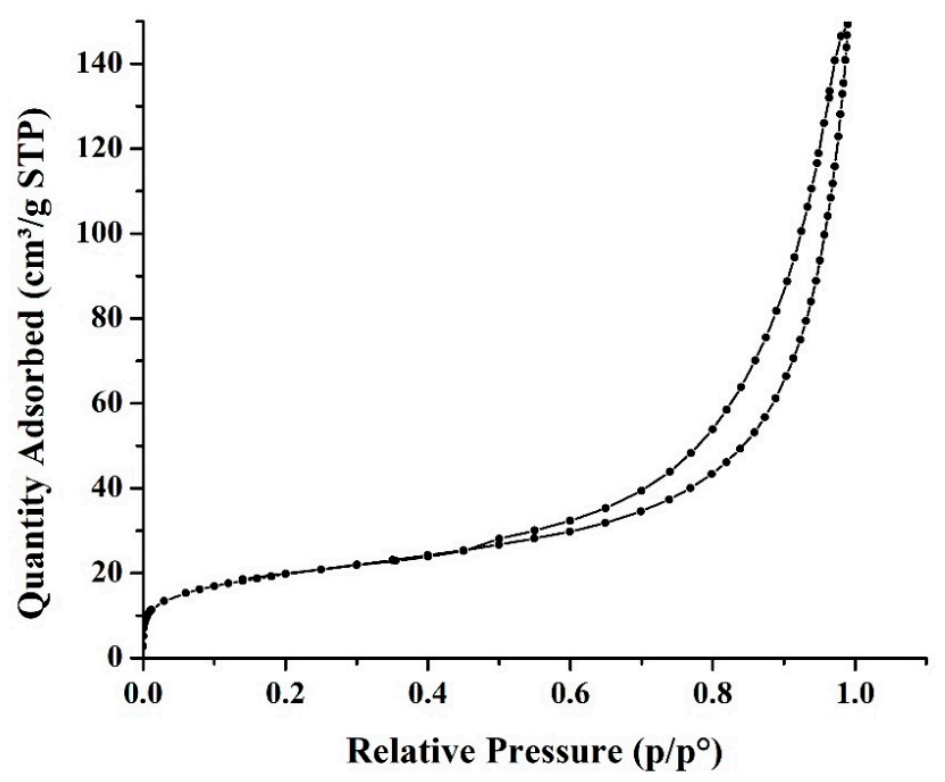

Figure 7. $\mathrm{N}_{2}$ adsorption-desorption isotherms.

\subsubsection{Zeta Potential}

It is crucial to classify the surface behavior's features in the provided aqueous solutions along with the assessment of the suspension stability [49]. Thus, the zeta potential was used to measure the electrical potential on hybrid CNTs' surface. The numerous $\mathrm{pH}$ levels determined the various samples' zeta potential and their differences. As $10 \mathrm{mg}$ of hybrid CNTs in $20 \mathrm{~mL}$ were dispersed, the results observed that zeta potential values varied from 0.111 to $-23(\mathrm{mV})$ in the $\mathrm{pH}$ range of 3-11, as shown in Table 3. The surface charge of hybrid CNTs is positive in acidic medium ( $\mathrm{pH}<\mathrm{pHpzc}$ ) [50]. There was also a noticeable reduction in surface charge, which was more negative when $\mathrm{pH}>\mathrm{pHpzc}$, causing easy interaction with the positive ions and hybrid CNTs' surface, and thus, finally affecting the high adsorption process caused by electrostatic interaction [51].

Table 3. Zeta potential results of hybrid CNTs with different $\mathrm{pH}$ values.

\begin{tabular}{ccc}
\hline Sample & $\mathbf{p H}$ & Zeta Potential (MV) \\
\hline 1 & 3 & 0.111 \\
2 & 5 & -5.255 \\
3 & 7 & -7.602 \\
4 & 9 & -10.558 \\
5 & 11 & -23 \\
\hline
\end{tabular}

\subsection{Application Studies}

\subsubsection{Optimization Study}

This study considered 17 experimental runs to evaluate optimum adsorption factors by applying RSM. Thus, the CCD model was used to conduct the experiment. The interaction effect of factors (hybrid CNTs dosage, $\mathrm{pH}$, and contact time) was investigated by fixing $5 \mathrm{mg} / \mathrm{L} \mathrm{Al}^{3+}$ concentration. Adsorption processes (removal \% and capacity $\mathrm{mg} / \mathrm{g}$ ) were adopted as responses, as shown in Table 1 . The highest removal was $84 \%$ under adsorbent dosage of $13.5 \mathrm{mg} / \mathrm{g}, \mathrm{pH}$ of 7 , and contact time of $22.22 \mathrm{~min}$. However, the highest capacity was $19.95 \mathrm{mg} / \mathrm{g}$ at an adsorbent dosage of $5.50 \mathrm{mg} / \mathrm{g}$, $\mathrm{pH}$ of 4 , and contact time of $18.56 \mathrm{~min}$. The experimental and predicted values were noted to have a close correlation (R2) of $\mathrm{Al}^{3+}$ removal and capacity to be 0.9367 and 0.9779 , respectively. 
The analysis of variance (ANOVA) outcomes for two responses is presented in Tables 4 and 5, indicating models F-values that were 3.99 and 14.14 in removal and capacity, respectively. This shows that both models are considerable. In this study, the equations of removal (\%) were transferred to inverse sqrt $(y=1 / \sqrt{ }(y+k))$ and applied according to Equation (1). Furthermore, the capacity of the significant model was quadratic, which was measured according to Equation (2):

$$
\begin{aligned}
& \text { 1.0/Sqrt (Removal) } \\
& =+0.10+0.029 A-0.086 B-0.031 C+0.033 A B-7.407 E \\
& -003 A C+0.11 B C+9.708 E-003 A^{2}+0.12 B^{2}+0.016 C^{2} \\
& \text { Capacity }=+37.10-24.03 A+20.46 B+1.03 C-21.33 A B-1.17 A C-6.05 B C \\
& +21.00 A^{2}-18.34 B^{2}-6.45 C^{2}
\end{aligned}
$$

where $A$ is Dosage, $B$ is $\mathrm{pH}$, and $C$ is contact time.

The comparison between theoretical and experimental values is revealed in Figure 8 for removal $(\%)$ and capacity $(\mathrm{mg} / \mathrm{g})$. Meanwhile, both the experimental and the theoretical values that were expected by the models established in this research were found to be very close. Therefore, we came to the conclusion that both models had effectively accomplished the interconnection between the process variables.
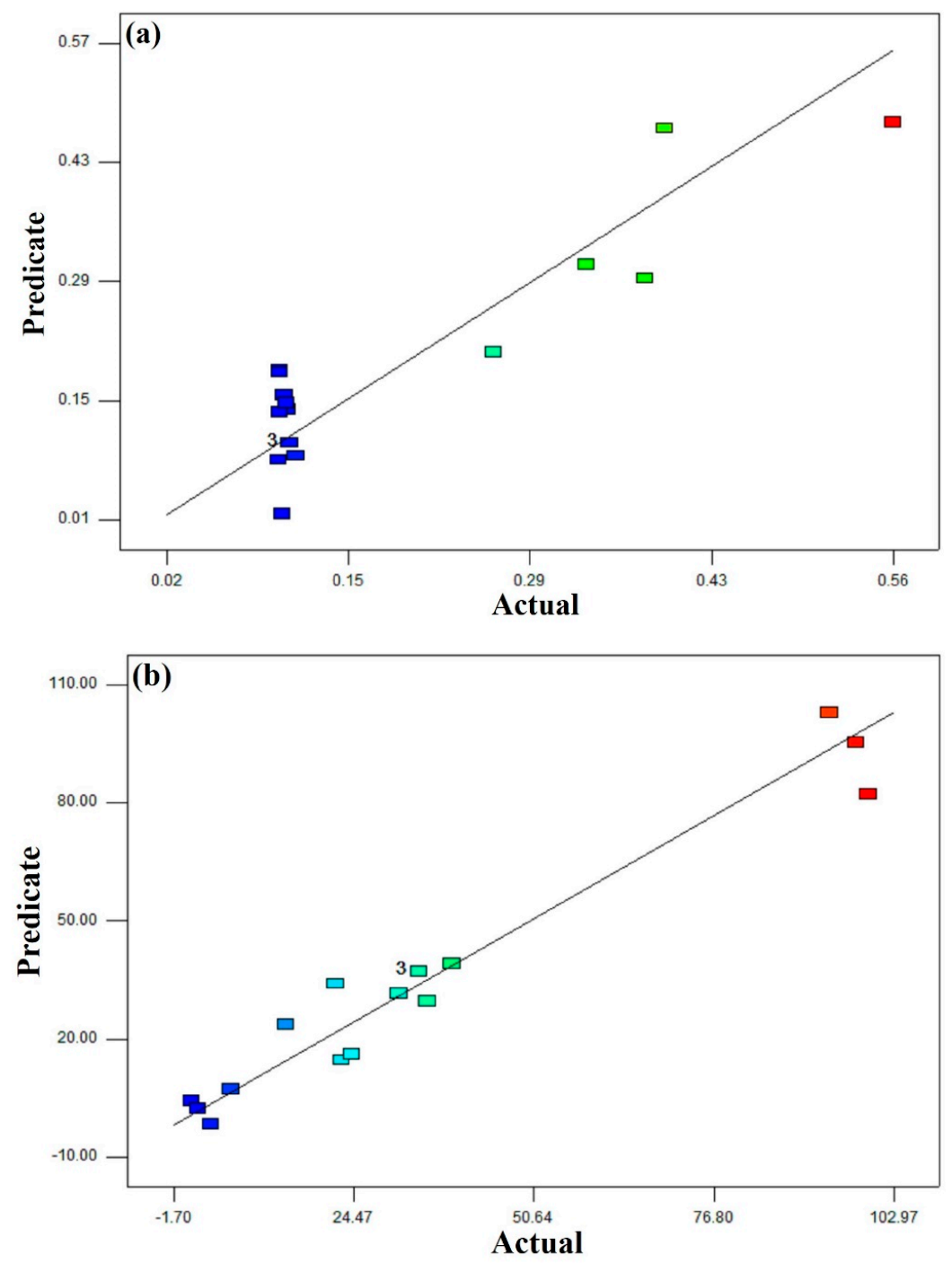

Figure 8. Parity plot of actual and predicate values of (a) removal (\%) and (b) capacity (mg/g). 
Table 4. ANOVA for $\mathrm{Al}^{3+}$ removal of hybrid CNTs.

\begin{tabular}{cccccc}
\hline Source & Sum of Squares & df & Mean Square & F Value & P-Value Prob > F \\
\hline Model & 0.27 & 9 & 0.030 & 3.99 & 0.0409 \\
A-Dose & $8.642 \times 10^{-3}$ & 1 & $8.642 \times 10^{-3}$ & 1.14 & 0.3209 \\
B-pH & 0.074 & 1 & 0.074 & 9.81 & 0.0165 \\
C-Contact Time & $9.866 \times 10^{-3}$ & 1 & $9.866 \times 10^{-3}$ & 1.30 & 0.2913 \\
AB & $8.801 \times 10^{-3}$ & 1 & $8.801 \times 10^{-3}$ & 1.16 & 0.3168 \\
AC & $4.389 \times 10^{-4}$ & 1 & $4.389 \times 10^{-4}$ & 0.058 & 0.8167 \\
BC & 0.092 & 1 & 0.092 & 12.16 & 0.0102 \\
A $^{2}$ & $2.525 \times 10^{-4}$ & 1 & $2.525 \times 10^{-4}$ & 0.033 & 0.8603 \\
$\mathrm{~B}^{2}$ & 0.040 & 1 & 0.040 & 5.32 & 0.0544 \\
$\mathrm{C}^{2}$ & $6.937 \times 10^{-4}$ & 1 & $6.937 \mathrm{E} \times 10^{-4}$ & 0.092 & 0.7710 \\
\hline
\end{tabular}

Table 5. ANOVA for $\mathrm{Al}^{3+}$ capacity of hybrid CNTs.

\begin{tabular}{cccccc}
\hline Source & Sum of Squares & df & Mean Square & F Value & P - Value Prob $>$ F \\
\hline Model & 15582.14 & 9 & 1731.35 & 14.14 & 0.0010 \\
A-Dose & 5774.65 & 1 & 5774.65 & 47.17 & 0.0002 \\
B-pH & 4186.28 & 1 & 4186.28 & 34.19 & 0.0006 \\
C-Contact Time & 10.58 & 1 & 10.58 & 0.086 & 0.7774 \\
AB & 3638.90 & 1 & 3638.90 & 29.72 & 0.0010 \\
AC & 11 & 1 & 11 & 0.090 & 0.7731 \\
BC & 292.46 & 1 & 292.46 & 2.39 & 0.1661 \\
A $^{2}$ & 1181.14 & 1 & 1181.14 & 9.65 & 0.0172 \\
B $^{2}$ & 901.39 & 1 & 901.39 & 7.36 & 0.0301 \\
C $^{2}$ & 111.47 & 1 & 111.47 & 0.91 & 0.3718 \\
\hline
\end{tabular}

\subsubsection{Effect of Factors on Optimization of Adsorption of $\mathrm{Al}^{3+}$ by Hybrid CNTs}

The section examines the interaction effect of adsorbent dosage and $\mathrm{pH}$ on adsorption processes considering removal \% and capacity $\mathrm{mg} / \mathrm{g}$. Figure 9 illustrates the three-dimensional surface plot, indicating that the effect was more significant between adsorbent dosage and $\mathrm{pH}$ on adsorption processes. Thus, it might be related to the increase in the adsorbent amount, which in return increased the active sites' concentration. As a result, the adsorption solution electrostatic charge was regulated in accordance with the desired adsorption level by eliminating the competitive $\mathrm{H}^{+}$cations. The adsorbent dosage directly increased with removal when the $\mathrm{pH}$ and contact time were established. In the meantime, when the adsorbent dosage increased, the capacity declined. This might be associated with the adsorption dosage's increase and the active adsorption sites' conglomeration or overlapping $[52,53]$.

In contrast, the interaction impact of contact time and $\mathrm{pH}$ on adsorption processes is shown in Figure 9. The system's failure to reach equilibrium led to a direct correlation of time with removal (\%) and capacity (mg/g). Removal (\%) increased with an increase of $\mathrm{pH}$ to 7 , and then it decreased as $\mathrm{pH}$ increased. Similarly, the capacity $(\mathrm{mg} / \mathrm{g})$ was detected to reach its maximum at a $\mathrm{pH}$ of 4 , after which it became steady [54].

Toxic metals are well-known precipitators when $\mathrm{pH}$ values are high [55]. Therefore, a section of $\mathrm{Al}$ in the solution is precipitated in the form of $\mathrm{Al}^{3+}\left(\mathrm{NO}_{3}\right)$ because of the impact of $\mathrm{OH}^{-}$anions that are found in the solution [56]. Thus, the initial concentration measurement was taken after adjusting the $\mathrm{pH}$. Consequently, there would be minimum precipitation effects on capacity and removal of hybrid CNTs. Without considering the precipitation phenomena, the overall number of $\mathrm{H}^{+}$cations decreased because of the increase in $\mathrm{pH}$, which was believed to be competing with the $\mathrm{Al}^{3+}$ cations of occupying the active sites on the adsorbent. Furthermore, the surface charge of adsorbents could be enhanced when the $\mathrm{pH}$ is high [47]. 

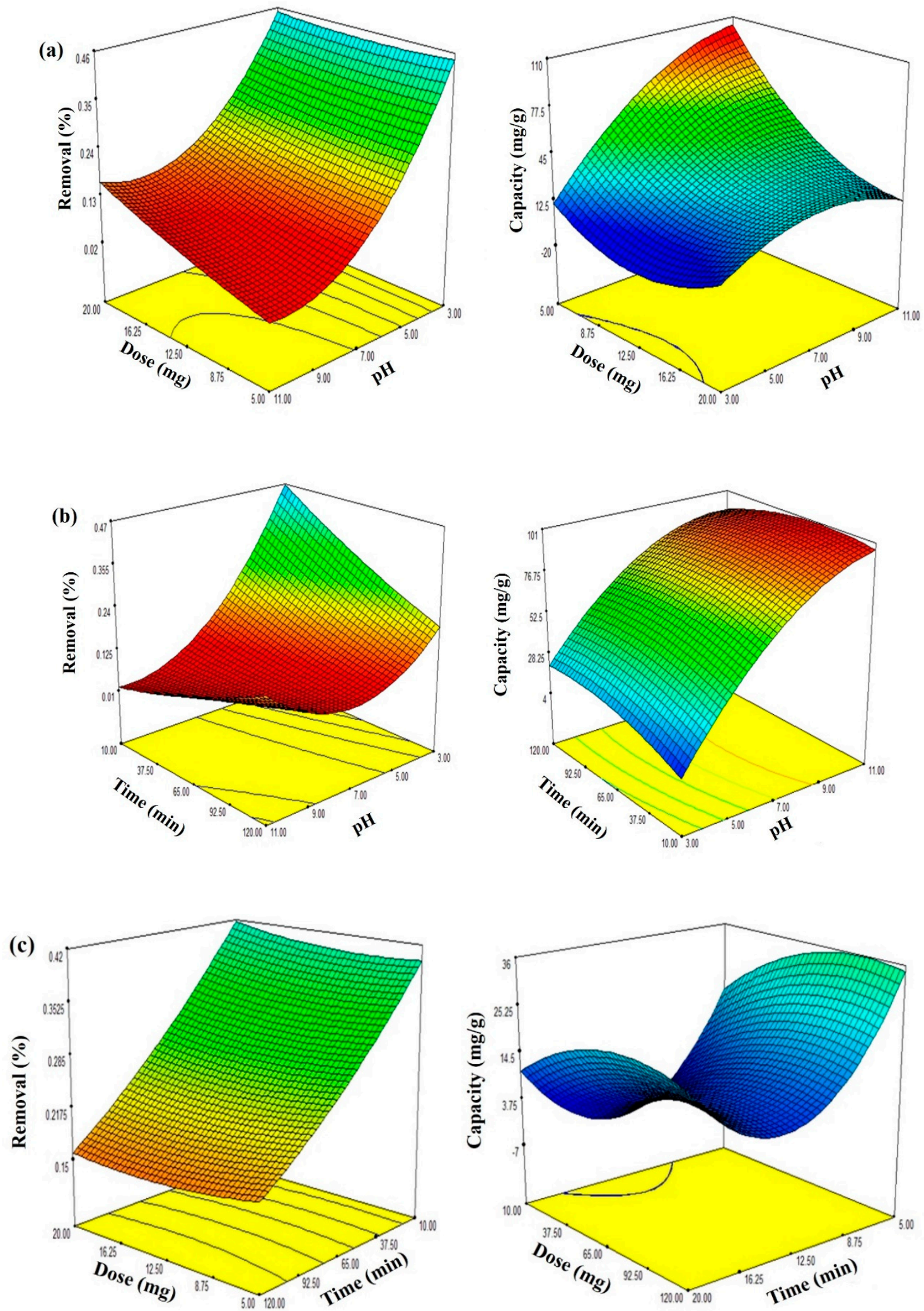

Figure 9. Surface response plots for the effects of (a) $\mathrm{pH}$ and hybrid CNTs dose, (b) $\mathrm{pH}$ and contact time, and (c) hybrid CNTs dose and contact time. 


\subsubsection{Adsorption Studies}

\section{Kinetics Studies}

The hybrid CNTs' adsorbent reaction behavior could be examined through kinetic behavior. For this experimental data, three kinetic models were used, including pseudo-first-order, pseudo-second-order, and the intraparticle diffusion model $[57,58]$. To conduct the kinetic study, the $\mathrm{Al}^{3+}$ that was included varied in concentrations from 3,5 , and $10 \mathrm{mg} / \mathrm{L}$, while the absorption dosage value was fixed at a $13.5 \mathrm{mg}$ and $\mathrm{pH}$ of 7 at various time intervals awaiting for the equilibrium state to be attained. According to the three models, it was revealed that the pseudo-second-order fitted better at various $\mathrm{Al}^{3+}$ concentrations, which was expressed by a higher correlation coefficient R2. Figure 10 displays the outcomes of the pseudo-second-order. Furthermore, the three applied models for kinetic results are given in Table 6.

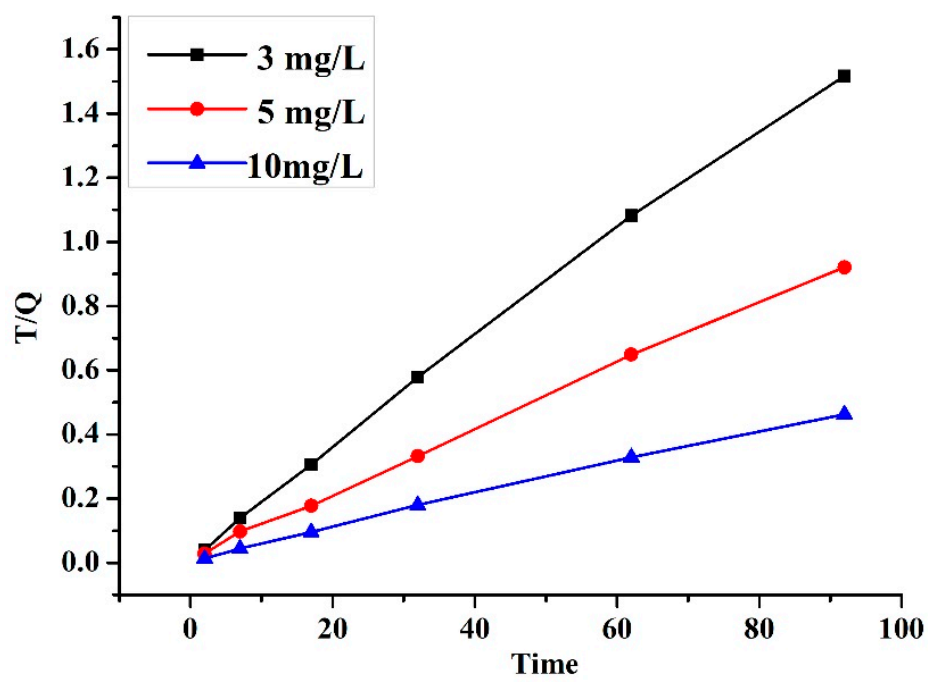

Figure 10. The plot of pseudo-second-order kinetic for $\mathrm{Al}^{3+}$ adsorption on hybrid CNTs.

Table 6. Adsorption kinetics and correlation coefficient.

\begin{tabular}{cccccc}
\hline & & & $\begin{array}{c}\text { Pseudo-First-Order } \\
\boldsymbol{l n}\left(\boldsymbol{q}_{\boldsymbol{c}}-\boldsymbol{q}_{t}\right) \text { vs time }(t)\end{array}$ & $\begin{array}{c}\text { Pseudo-Second-Order } \\
\left(t / q_{c} \text { vs } t\right)\end{array}$ & $\begin{array}{c}\text { Intraparticle } \\
\left(\boldsymbol{q}_{\boldsymbol{c}} \text { vs } t^{\mathbf{0 . 5}}\right)\end{array}$ \\
\hline Dose $\mathbf{~} \mathbf{g}$ & $\mathbf{p H}$ & $\mathbf{C}_{\mathbf{0}} \mathbf{~} \mathbf{~ g} / \mathbf{L}$ & $\mathbf{R}^{\mathbf{2}}$ & $\mathbf{R}^{\mathbf{2}}$ & $\mathbf{R}^{\mathbf{2}}$ \\
\hline 13.5 & 7 & 3 & 0.9091 & 0.9583 & 0.8769 \\
13.5 & 7 & 5 & 0.7084 & 0.999 & 0.522 \\
13.5 & 7 & 10 & 0.8275 & 0.8736 & 0.874 \\
\hline
\end{tabular}

Isotherm Studies

The isotherm study was used to perform the $\mathrm{Al}^{3+}$ ion adsorption into the hybrid CNTs adsorbent surface through both the Freundlich and Langmuir isotherm models. To conduct the adsorption isotherm study, $\mathrm{Al}^{3+}$ was used at multiple concentrations of 3, 5, 10, 20, 30, and $40 \mathrm{mg} / \mathrm{L}$. Moreover, the $\mathrm{pH}$ was of 7 , while the hybrid CNTs' dosage was $13.5 \mathrm{mg}$, and these values were indicated by an optimization study [59]. Figure 11 presents the Freundlich and Langmuir isotherm outcomes. Based on these results, it was discovered that Freundlich was a more suitable fit for $\mathrm{Al}^{3+}$ adsorption into hybrid CNTs' adsorbent surface. The coefficient of correlation (R2) attained from the Freundlich model was 0.9802 , while the $\mathrm{R} 2$ from the Langmuir model was 0.9738 , which indicated that the adsorption of $\mathrm{Al}^{3+}$ occurred on the heterogeneous surface with an interaction between the molecules of the adsorbent. Furthermore, Table 7 illustrates a comparison between the maximum adsorption capacities of hybrid CNTs with other nano absorbents materials. 

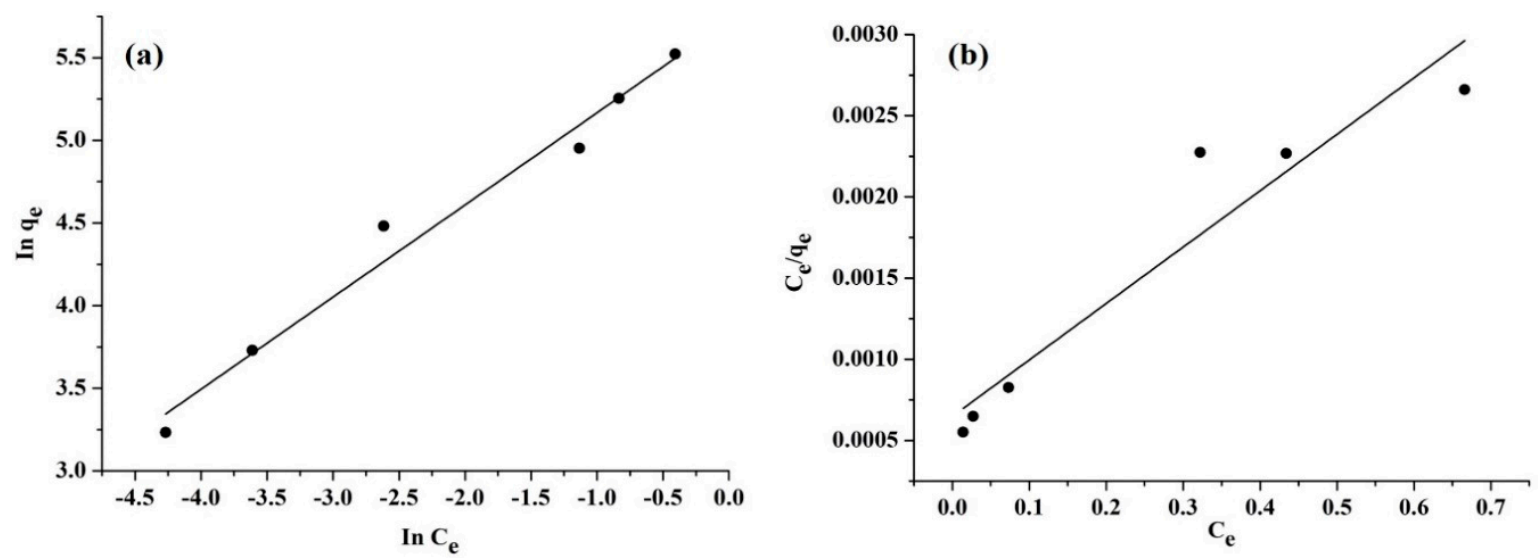

Figure 11. Plots of isotherm models (a) Freundlich and (b) Langmuir.

Table 7. Comparison between the maximum adsorption capacity of hybrid CNTs with other absorbents.

\begin{tabular}{cccc}
\hline Absorbent & Pollutant & Capacity $(\mathbf{m g} / \mathbf{g})$ & References \\
\hline Hybrid CNTs & $\mathrm{Al}^{3+}$ & 347.88 & This study \\
MWCNT & $\mathrm{RhB}$ & 568.181 & {$[60]$} \\
mesoporous composite $\gamma-\mathrm{Fe}_{2} \mathrm{O}_{3} / \alpha-\mathrm{Fe}_{2} \mathrm{O}_{3} / \mathrm{CA}$ & $\mathrm{RhB}$ & 165 & {$[61]$} \\
$\mathrm{P} n, n$-CNTs & $\mathrm{MO}$ & 263.14 & {$[62]$} \\
magnetic-modified multi-walled carbon nanotubes & $\mathrm{MB}$ & 48.1 & {$[63]$} \\
\hline
\end{tabular}

\section{Conclusions}

This study demonstrated that hybrid CNTs could be successfully grown on bio-PAC impregnated with Fe catalyst (bio-PAC/Fe) using acetylene as carbon source and implementing the CVD method under $550{ }^{\circ} \mathrm{C}$ for $47 \mathrm{~min}$. The synthesized hybrid CNTs were characterized by EDX, FESEM, and TEM analyses, which confirmed the growth. Thus, results were arranged with FTIR, XRD, BET, TGA, and zeta potential, all of which revealed graphitic structure formation of CNTs that was suggested to be a good adsorbent. Optimum parameters for the $\mathrm{Al}^{3+}$ adsorption process were utilized by RSM, and it was found that the hybrid CNTs' dose was $13.5 \mathrm{mg} / \mathrm{g}$, $\mathrm{pH}$ of 7 , and contact time of $22.22 \mathrm{~min}$. The adsorption kinetics and isotherms models revealed that the adsorption process was best fitted in the pseudo-second-order and Freundlich model, respectively. Moreover, the maximum adsorption capacity was $347.88 \mathrm{mg} / \mathrm{g}$. Thus, the results revealed that the quality structure of hybrid CNTs was attributed to the supported catalyst $(\mathrm{Fe})$ on the bio-PAC substrate. Moreover, the hybrid CNTs on bio-PAC/Fe, which was originally synthesized from biomass, had a cost-effective adsorbent quality of having the potential to be expanded to other pollutants in wastewater and other applications.

Author Contributions: Synthesis and laboratory work, A.O.B.; writing-original draft preparation, A.O.B and M.A.A.; Supervision, M.M.H. and W.Z.W.Y.; Review and Editing, Y.A.-D. Formal analysis, M.M.H. All authors have read and agreed to the published version of the manuscript.

Funding: This research received no external funding.

Acknowledgments: The authors gratefully acknowledge Universiti Kebangsaan Malaysia, Marlia M. Hanafiah, and Universiti of Malaya for providing facilities.

Conflicts of Interest: The authors declare no conflict of interest.

\section{References}

1. Basheer, A.; M Hanafiah, M.; Abdulhakim Alsaadi, M.; Al-Douri, Y.; Malek, M.A.; Mohammed Aljumaily, M.; Saadi Fiyadh, S. Synthesis and characterization of natural extracted precursor date palm fibre-based activated carbon for aluminum removal by RSM optimization. Processes 2019, 7, 249. [CrossRef]

2. Mishra, M.; Chauhan, M. Biosorption as a Novel Approach for Removing Aluminium from Water Treatment Plant Residual-A Review. In Water Quality Management; Springer: Berlin, Germany, 2018; pp. 93-99. 
3. Mohd-Salleh, S.N.A.; Mohd-Zin, N.S.; Othman, N. A Review of Wastewater Treatment using Natural Material and Its Potential as Aid and Composite Coagulant. Sains Malays. 2019, 48, 155-164. [CrossRef]

4. Al-Muhtaseb, S.A.; El-Naas, M.H.; Abdallah, S. Removal of aluminum from aqueous solutions by adsorption on date-pit and BDH activated carbons. J. Hazard. Mater. 2008, 158, 300-307. [CrossRef] [PubMed]

5. Al-Raad, A.A.; Hanafiah, M.M.; Naje, A.S.; Ajeel, M.A.; O Basheer, A.; Ali Aljayashi, T.; Ekhwan Toriman, M. Treatment of Saline Water Using Electrocoagulation with Combined Electrical Connection of Electrodes. Processes 2019, 7, 242. [CrossRef]

6. Huang, Y.; Zeng, X.; Guo, L.; Lan, J.; Zhang, L.; Cao, D. Heavy metal ion removal of wastewater by zeolite-imidazolate frameworks. Sep. Purif. Technol. 2018, 194, 462-469. [CrossRef]

7. Fang, L.; Li, L.; Qu, Z.; Xu, H.; Xu, J.; Yan, N. A novel method for the sequential removal and separation of multiple heavy metals from wastewater. J. Hazard. Mater. 2018, 342, 617-624. [CrossRef]

8. Ang, W.L.; Mohammad, A.W.; Johnson, D.; Hilal, N. Forward osmosis research trends in desalination and wastewater treatment: A review of research trends over the past decade. J. Water Process Eng. 2019, 31, 100886. [CrossRef]

9. Feng, Y.; Yang, L.; Liu, J.; Logan, B.E. Electrochemical technologies for wastewater treatment and resource reclamation. Environ. Sci. Water Res. Technol. 2016, 2, 800-831. [CrossRef]

10. Thue, P.S.; dos Reis, G.S.; Lima, E.C.; Sieliechi, J.M.; Dotto, G.; Wamba, A.G.; Dias, S.L.; Pavan, F.A. Activated carbon obtained from sapelli wood sawdust by microwave heating for o-cresol adsorption. Res. Chem. Intermed. 2017, 43, 1063-1087. [CrossRef]

11. Kizito, S.; Wu, S.; Kirui, W.K.; Lei, M.; Lu, Q.; Bah, H.; Dong, R. Evaluation of slow pyrolyzed wood and rice husks biochar for adsorption of ammonium nitrogen from piggery manure anaerobic digestate slurry. Sci. Total Environ. 2015, 505, 102-112. [CrossRef]

12. Intani, K.; Latif, S.; Kabir, A.R.; Müller, J. Effect of self-purging pyrolysis on yield of biochar from maize cobs, husks and leaves. Bioresour. Technol. 2016, 218, 541-551. [CrossRef]

13. Zhao, H.; Sun, W.; Wu, X.; Gao, B. The properties of the self-compacting concrete with fly ash and ground granulated blast furnace slag mineral admixtures. J. Clean. Prod. 2015, 95, 66-74. [CrossRef]

14. Fiyadh, S.S.; AlSaadi, M.A.; Jaafar, W.Z.B.; AlOmar, M.K.; Fayaed, S.S.; Mohd, N.S.B.; Hin, L.S.; El-Shafie, A. Review on heavy metal adsorption processes by carbon nanotubes. J. Clean. Prod. 2019, 230, 783-793. [CrossRef]

15. Chen, G.; Liu, X.; Brookes, P.C.; Xu, J. Opportunities for phytoremediation and bioindication of arsenic contaminated water using a submerged aquatic plant: Vallisneria natans (Lour.) Hara. Int. J. Phytorem. 2015, 17, 249-255. [CrossRef]

16. Murray, C.C.; Vatankhah, H.; McDonough, C.A.; Nickerson, A.; Hedtke, T.T.; Cath, T.Y.; Higgins, C.P.; Bellona, C.L. Removal of per-and polyfluoroalkyl substances using super-fine powder activated carbon and ceramic membrane filtration. J. Hazard. Mater. 2019, 366, 160-168. [CrossRef]

17. Lee, S.; Ko, K.; Youk, J.; Lim, D.; Jeong, W. Preparation and Properties of Carbon Fiber/Carbon Nanotube Wet-Laid Composites. Polymers 2019, 11, 1597. [CrossRef]

18. Puglisi, R.A.; Bongiorno, C.; Caccamo, S.; Fazio, E.; Mannino, G.; Neri, F.; Scalese, S.; Spucches, D.; La Magna, A. Chemical Vapor Deposition Growth of Silicon Nanowires with Diameter Smaller Than $5 \mathrm{~nm}$. ACS Omega 2019, 4, 17967-17971. [CrossRef]

19. Xiang, X.; Zhang, L.; Hima, H.I.; Li, F.; Evans, D.G. Co-based catalysts from Co/Fe/Al layered double hydroxides for preparation of carbon nanotubes. Appl. Clay Sci. 2009, 42, 405-409. [CrossRef]

20. Aljumaily, M.M.; Alsaadi, M.A.; Hashim, N.A.; Alsalhy, Q.F.; Mjalli, F.S.; Atieh, M.A.; Al-Harrasi, A. PVDF-co-HFP/superhydrophobic acetylene-based nanocarbon hybrid membrane for seawater desalination via DCMD. Chem. Eng. Res. Des. 2018, 138, 248-259. [CrossRef]

21. Alayan, H.M.; Alsaadi, M.A.; AlOmar, M.K.; Hashim, M.A. Growth and optimization of carbon nanotubes in powder activated carbon for an efficient removal of methylene blue from aqueous solution. Environ. Technol. 2019, 40, 2400-2415. [CrossRef]

22. Yahyazadeh, A.; Khoshandam, B. Carbon nanotube synthesis via the catalytic chemical vapor deposition of methane in the presence of iron, molybdenum, and iron-molybdenum alloy thin layer catalysts. Results Phys. 2017, 7, 3826-3837. [CrossRef] 
23. Zhao, Y.; Choi, J.; Kim, P.; Fei, W.; Lee, C.J. Large-scale synthesis and characterization of super-bundle single-walled carbon nanotubes by water-assisted chemical vapor deposition. RSC Adv. 2015, 5, 30564-30569. [CrossRef]

24. Chen, G.; Davis, R.C.; Kimura, H.; Sakurai, S.; Yumura, M.; Futaba, D.N.; Hata, K. The relationship between the growth rate and the lifetime in carbon nanotube synthesis. Nanoscale 2015, 7, 8873-8878. [CrossRef]

25. Mamtm, A.; Ma'an, F.; Zahirah, A.; Yehya, M.; Mohammed, A. Optimisation of arsenic adsorption from water by carbon nanofibres grown on powdered activated carbon impregnated with nickel. J. Appl. Sci. 2009, 9, 3180-3183.

26. Aljumaily, M.M.; Alsaadi, M.A.; Hashim, N.A.; Alsalhy, Q.F.; Das, R.; Mjalli, F. Embedded high-hydrophobic CNMs prepared by CVD technique with PVDF-co-HFP membrane for application in water desalination by DCMD. Desalin. Water Treat. 2019, 142, 37-48. [CrossRef]

27. AlOmar, M.K.; Alsaadi, M.A.; Hayyan, M.; Akib, S.; Ibrahim, R.K.; Hashim, M.A. Lead removal from water by choline chloride based deep eutectic solvents functionalized carbon nanotubes. J. Mol. Liq. 2016, 222, 883-894. [CrossRef]

28. Fiyadh, S.S.; AlOmar, M.K.; Binti Jaafar, W.Z.; AlSaadi, M.A.; Fayaed, S.S.; Binti Koting, S.; Lai, S.H.; Chow, M.F.; Ahmed, A.N.; El-Shafie, A. Artificial Neural Network Approach for Modelling of Mercury Ions Removal from Water Using Functionalized CNTs with Deep Eutectic Solvent. Int. J. Mol. Sci. 2019, 20, 4206. [CrossRef]

29. Pakade, V.E.; Tavengwa, N.T.; Madikizela, L.M. Recent advances in hexavalent chromium removal from aqueous solutions by adsorptive methods. RSC Adv. 2019, 9, 26142-26164. [CrossRef]

30. Boscarino, S.; Filice, S.; Sciuto, A.; Libertino, S.; Scuderi, M.; Galati, C.; Scalese, S. Investigation of ZnO-decorated CNTs for UV Light Detection Applications. Nanomaterials 2019, 9, 1099. [CrossRef]

31. Ionescu, M.I. Direct synthesis of carbon nanotubes on metallic foams as a cathode material with high mass load for lithium-air batteries. RSC Adv. 2017, 7, 30365-30369. [CrossRef]

32. Minakshi, M.; Mitchell, D.R.; Baur, C.; Chable, J.; Barlow, A.J.; Fichtner, M.; Banerjee, A.; Chakraborty, S.; Ahuja, R. Phase evolution in calcium molybdate nanoparticles as a function of synthesis temperature and its electrochemical effect on energy storage. Nanoscale Adv. 2019, 1, 565-580. [CrossRef]

33. Roe, D.P.; Xu, R.; Roberts, C.B. Influence of a carbon nanotube support and supercritical fluid reaction medium on Fe-catalyzed Fischer-Tropsch synthesis. Appl. Catal. A Gen. 2017, 543, 141-149. [CrossRef]

34. Shen, D.; Liu, J.; Gan, L.; Huang, N.; Long, M. Green synthesis of Fe $3 \mathrm{O} 4$ /cellulose/polyvinyl alcohol hybride aerogel and its application for dye removal. J. Polym. Environ. 2018, 26, 2234-2242. [CrossRef]

35. Syafiuddin, A.; Salmiati, S.; Hadibarata, T.; Kueh, A.B.H.; Salim, M.R.; Zaini, M.A.A. Silver Nanoparticles in the Water Environment in Malaysia: Inspection, characterization, removal, modeling, and future perspective. Sci. Rep. 2018, 8, 986. [CrossRef]

36. Aljumaily, M.M.; Alsaadi, M.A.; Das, R.; Hamid, S.B.A.; Hashim, N.A.; AlOmar, M.K.; Alayan, H.M.; Novikov, M.; Alsalhy, Q.F.; Hashim, M.A. Optimization of the synthesis of superhydrophobic carbon nanomaterials by chemical vapor deposition. Sci. Rep. 2018, 8, 2778. [CrossRef]

37. Minakshi, M.; Barmi, M.J.; Jones, R.T. Rescaling metal molybdate nanostructures with biopolymer for energy storage having high capacitance with robust cycle stability. Dalton Trans. 2017, 46, 3588-3600. [CrossRef]

38. Țucureanu, V.; Matei, A.; Avram, A.M. FTIR spectroscopy for carbon family study. Crit. Rev. Anal. Chem. 2016, 46, 502-520. [CrossRef]

39. ROSNAN, N.A.; Haan, T.Y.; Mohammad, A.W. The Effect of ZnO Loading for the Enhancement of PSF/ZnO-GO Mixed Matrix Membrane Performance. Sains Malays. 2018, 47, 2035-2045. [CrossRef]

40. Gupta, V.K.; Agarwal, S.; Saleh, T.A. Synthesis and characterization of alumina-coated carbon nanotubes and their application for lead removal. J. Hazard. Mater. 2011, 185, 17-23. [CrossRef]

41. Rodiles, X.; Reguero, V.; Vila, M.; Alemán, B.; Arévalo, L.; Fresno, F.; de la Peña O’Shea, V.; Vilatela, J. Carbon nanotube synthesis and spinning as macroscopic fibers assisted by the ceramic reactor tube. Sci. Rep. 2019, 9, 9239. [CrossRef]

42. Misra, A.; Tyagi, P.K.; Rai, P.; Misra, D. FTIR Spectroscopy of multiwalled carbon nanotubes: A Simple approachto study the nitrogen doping. J. Nanosci. Nanotechnol. 2007, 7, 1820-1823. [CrossRef] 
43. Quan, C.; Li, A.; Gao, N. Synthesis of carbon nanotubes and porous carbons from printed circuit board waste pyrolysis oil. J. Hazard. Mater. 2010, 179, 911-917. [CrossRef]

44. Bellanger, H.; Darmanin, T.; Taffin de Givenchy, E.; Guittard, F. Chemical and physical pathways for the preparation of superoleophobic surfaces and related wetting theories. Chem. Rev. 2014, 114, 2694-2716. [CrossRef]

45. Hildago-Oporto, P.; Navia, R.; Hunter, R.; Coronado, G.; Gonzalez, M. Synthesis of carbon nanotubes using biochar as precursor material under microwave irradiation. J. Environ. Manag. 2019, 244, 83-91.

46. Lawal, I.A.; Dolla, T.H.; Pruessner, K.; Ndungu, P. Synthesis and characterization of deep eutectic solvent functionalized $\mathrm{CNT} / \mathrm{ZnCo} 2 \mathrm{O} 4$ nanostructure: Kinetics, isotherm and regenerative studies on Eosin Y adsorption. J. Environ. Chem. Eng. 2019, 7, 102877. [CrossRef]

47. Alayan, H.M.; Alsaadi, M.A.; Abo-Hamad, A.; AlOmar, M.K.; Aljumaily, M.M.; Das, R.; Hashim, M.A. Hybridizing carbon nanomaterial with powder activated carbon for an efficient removal of Bisphenol A from water: The optimum growth and adsorption conditions. Desalin. Water Treat. 2017, 95, 128-143.

48. Lee, W.J.; Lee, J.M.; Kochuveedu, S.T.; Han, T.H.; Jeong, H.Y.; Park, M.; Yun, J.M.; Kwon, J.; No, K.; Kim, D.H. Biomineralized N-doped CNT/TiO2 core/shell nanowires for visible light photocatalysis. ACS Nano 2011, 6, 935-943. [CrossRef]

49. Fraczek-Szczypta, A.; Dlugon, E.; Weselucha-Birczynska, A.; Nocun, M.; Blazewicz, M. Multi walled carbon nanotubes deposited on metal substrate using EPD technique. A spectroscopic study. J. Mol. Struct. 2013, 1040, 238-245. [CrossRef]

50. Ngulube, T.; Gumbo, J.; Masindi, V.; Maity, A. Preparation and characterisation of high performing magnesite-halloysite nanocomposite and its application in the removal of methylene blue dye. J. Mol. Struct. 2019, 1184, 389-399. [CrossRef]

51. Gatabi, M.P.; Moghaddam, H.M.; Ghorbani, M. Point of zero charge of maghemite decorated multiwalled carbon nanotubes fabricated by chemical precipitation method. J. Mol. Liq. 2016, 216, 117-125. [CrossRef]

52. Halder, G.; Sinha, K.; Dhawane, S. Defluoridation of wastewater using powdered activated carbon developed from Eichhornia crassipes stem: Optimization by response surface methodology. Desalin. Water Treat. 2015, 56, 953-966. [CrossRef]

53. AlOmar, M.K.; Alsaadi, M.A.; Hayyan, M.; Akib, S.; Ibrahim, M.; Hashim, M.A. Allyl triphenyl phosphonium bromide based DES-functionalized carbon nanotubes for the removal of mercury from water. Chemosphere 2017, 167, 44-52. [CrossRef]

54. Ahmad, N.S.; Radiman, S.; Yaacob, W.Z.W. Aggregation and Stability of Iron Oxide and Alumina Nanoparticles: Influences of $\mathrm{pH}$ and Humic Acid Concentration. Sains Malays. 2019, 48, 435-442. [CrossRef]

55. Bradl, H.B. Adsorption of heavy metal ions on soils and soils constituents. J. Colloid Interface Sci. 2004, 277, 1-18. [CrossRef]

56. Kumar, A.S.K.; Jiang, S.-J. Chitosan-functionalized graphene oxide: A novel adsorbent an efficient adsorption of arsenic from aqueous solution. J. Environ. Chem. Eng. 2016, 4, 1698-1713. [CrossRef]

57. Ashrafi, A.; Rahbar-Kelishami, A.; Shayesteh, H. Highly efficient simultaneous ultrasonic assisted adsorption of $\mathrm{Pb}$ (II) by Fe3O4@ MnO2 core-shell magnetic nanoparticles: Synthesis and characterization, kinetic, equilibrium, and thermodynamic studies. J. Mol. Struct. 2017, 1147, 40-47. [CrossRef]

58. Alvarez-Torrellas, S.; Boutahala, M.; Boukhalfa, N.; Munoz, M. Effective Adsorption of Methylene Blue dye onto Magnetic Nanocomposites. Modeling and Reuse Studies. Appl. Sci. 2019, 9, 4563. [CrossRef]

59. Lakkaboyana, S.K.; Khantong, S.; Asmel, N.K.; Yuzir, A.; Yaacob, W.Z.W. Synthesis of Copper Oxide Nanowires-Activated Carbon (AC@ CuO-NWs) and Applied for Removal Methylene Blue from Aqueous Solution: Kinetics, Isotherms, and Thermodynamics. J. Inorg. Organomet. Polym. Mater. 2019, 29, 1-11. [CrossRef]

60. Rong, J.; Rong, X.; Qiu, F.; Zhu, X.; Pan, J.; Zhang, T.; Yang, D. Facile preparation of glucose functionalized multi-wall carbon nanotubes and its application for the removal of cationic pollutants. Mater. Lett. 2016, 183, 9-13. [CrossRef]

61. Lin, Y.-F.; Chang, C.-Y. Magnetic mesoporous iron oxide/carbon aerogel photocatalysts with adsorption ability for organic dye removal. RSC Adv. 2014, 4, 28628-28631. [CrossRef] 
62. Ibrahim, R.K.; El-Shafie, A.; Hin, L.S.; Mohd, N.S.B.; Aljumaily, M.M.; Ibraim, S.; AlSaadi, M.A. A clean approach for functionalized carbon nanotubes by deep eutectic solvents and their performance in the adsorption of methyl orange from aqueous solution. J. Environ. Manag. 2019, 235, 521-534. [CrossRef]

63. Madrakian, T.; Afkhami, A.; Ahmadi, M.; Bagheri, H. Removal of some cationic dyes from aqueous solutions using magnetic-modified multi-walled carbon nanotubes. J. Hazard. Mater. 2011, 196, 109-114. [CrossRef]

(C) 2020 by the authors. Licensee MDPI, Basel, Switzerland. This article is an open access article distributed under the terms and conditions of the Creative Commons Attribution (CC BY) license (http://creativecommons.org/licenses/by/4.0/). 